\title{
Un modelo funerario de la escuela burgalesa: Las capillas centrales de la segunda mitad del siglo XV en Burgos
}

\author{
Elena Martín Martínez de Simón \\ Departamento de Ciencias Históricas y Geografía \\ Universidad de Burgos \\ elenamms@gmail.com/emm0052@alu.ubu.es
}

\section{RESUMEN}

Con esta comunicación se quiere poner de manifiesto la importancia de los Colonia y de la Catedral de Burgos para toda la arquitectura funeraria tardogótica y del primer Renacimiento, arquitectura que está influida por capillas anteriores de la propia Catedral y que, sobre todo, influirá en todas las construcciones funerarias posteriores. Los Colonia y sus promotores son capaces de crear una nueva tipología de capilla central, en muchos casos ochavada, cubierta con bóveda estrellada, a veces calada, cuya mejor representación es la Capilla de los Condestables. Este tipo de capillas se convertirá en un modelo representativo de la Escuela Burgalesa a partir de finales del siglo XV y se difundirá por el resto de la Península en el siglo XVI gracias a los herederos de los Colonia.

Palabras clave: Capillas Funerarias; Catedral de Burgos; Juan de Colonia; Simón de Colonia; Siglo XV.

\section{A funeral model of Burgos school: The central chapels of the second half of the XV century in Burgos}

\begin{abstract}
With this communication, I want to show the importance of Juan and Simon de Colonia and the Burgos Cathedral for the entire funeral late Gothic and Renaissance architecture. This architecture is influenced by previous chapels located in the Cathedral and, above all, it will influence in all subsequent funeral structures. The Colonia and their promoters are able to create a new typology of central chapel, often octagonal, covered with openwork star vault, sometimes, whose best representative is the Condestables Chapel. This type of chapels will become a typical model of Burgos School in the late fifteenth century and this will spread throughout the rest of the Peninsula in the Sixteenth century thanks to the heirs of the Colonia
\end{abstract}

Key words: Funeral Chapels; Burgos Cathedral; Juan de Colonia; Simón de Colonia; Fifteenth Century. 
Como es de sobra conocido, Alonso de Cartagena, al regresar a Castilla después de haber recorrido y conocido algunas de las ciudades más importantes de Europa, impone una nueva forma de hacer las cosas en el construir de Burgos a imitación de lo que había visto en ciudades alemanas y francesas. Bajo sus órdenes, el gran arquitecto alemán Hans Von Köln, Juan de Colonia, realiza las agujas de la catedral burgalesa al modo en que se estaban efectuando tanto en la ciudad de donde viene, como en el resto de Alemania. La construcción de éstas, así como su propagación en la arquitectura tardogótica castellana, es uno de los mejores ejemplos de la gran difusión de modelos que estos arquitectos extranjeros traen consigo a Castilla. Así, a partir de la vuelta del obispo burgalés, la arquitectura rompe con la tradición francesa impuesta hasta el momento, comenzando a basarse en la influencia alemana y flamenca de la mano de estos arquitectos que se asientan en Castilla, como Juan de Colonia en Burgos o Hanequin de Bruselas en otro de los focos más importantes del momento, Toledo.

Sin embargo, solemos centrarnos en las agujas o -más tarde y por arquitectos posteriores- en la difusión de las hallenkirchen, también de origen norte-europeo. Pero con frecuencia nos olvidamos de otra de las grandes innovaciones que Alonso de Cartagena y Juan de Colonia imponen en Burgos y que, igualmente, el condestable Álvaro de Luna junto con Hanequin de Bruselas, lo aplican en Toledo: las grandes capillas funerarias de planta centralizada.

Uno de los posibles modelos directos de esta nueva arquitectura es la Cartuja de Champmol, en Dijón, en la que, en medio del presbiterio de la iglesia de nave única, estaban los grandiosos sepulcros de los Duques de Borgoña ${ }^{1}$. El obispo burgalés conoce este ejemplo de espacio funerario con gran axialidad y centralidad cuando hace escala en la ciudad francesa. Además, según Tarín y Juaneda² ${ }^{2}$ Juan de Colonia pudo ser el arquitecto de los Duques de Borgoña y, por ello, conocer perfectamente los sepulcros de la Cartuja de Champmol así como la concepción de la propia iglesia monasterial, aunque esta teoría no está demostrada. Igualmente, Juan de Colonia tuvo que conocer en la ciudad de Colonia la iglesia martirial de San Gereón, un espacio prerrománico central, constituido como una gran elipse con capillas radiales y cubierto con una bóveda octopartita, a la manera de los martyria romanos ${ }^{3}$.

Juan de Colonia, como arquitecto de Alonso de Cartagena y de su Catedral, comienza a realizar diferentes capillas e iglesias basándose en la idea de ser espacios funerarios. Por tanto, este modelo de capillas funerarias con sepulcros exentos, situados normalmente en el centro de la capilla, se difunde a mediados del siglo XV gracias a la actuación de Juan de Colonia y de sus colaboradores y, por eso, es Burgos su centro más importante.

1 GARCÍA CUETOS, María Pilar, "En los límites de la sombra como arquetipo historiográfico. La llegada de Juan de Colonia y su aportación a la arquitectura tardogótica en Castilla”, en ALONSO RUIZ, Begoña, Los últimos arquitectos del Gótico, Santander, Universidad de Cantabria, 2010, pp. 79-81.

2 TARÍN Y JUANEDA, Francisco, La Real Cartuja de Miraflores (Burgos). Su historia y su descripción, Burgos, Hijos de Santiago Rodríguez, 1896, p. 314.

3 CARAZO, Eduardo y OTXOTORENA, Juan Miguel, Arquitecturas centralizadas. El espacio sacro de planta central: diez ejemplos en Castilla y León, Valladolid, Secretariado de Publicaciones de la Universidad de Valladolid, 1994, p. 65. 
Tradicionalmente, la arquitectura gótica de las grandes catedrales abre en la girola capillas de dimensiones reducidas y normalmente cubiertas con bóvedas sencillas, adaptadas al espacio, destinadas a ser capillas privadas de eclesiásticos e, incluso, de algún noble. En las naves, también son pequeños espacios que no alteran el resto de la estructura de la iglesia, como las capillas entre cada uno de los intercolumnios de las naves laterales realizadas de una manera simétrica y compacta. De igual manera, los enterramientos en los claustros se habían ido desarrollando, pasando de ser pequeños arcosolios en los muros en los siglos XIII y XIV a verdaderas capillas centralizadas a imitación de la sala capitular, cubiertas también con bóvedas complejas, a partir del siglo XIV y, sobre todo, en el XV, pero sin romper ese esquema unitario de la iglesia. Por tanto, las primeras capillas funerarias construidas en el siglo XV no son espacios desintegrados del templo en el que se levantan, como es el caso de la Capilla de la Visitación que, aun ocupando un espacio mayor que el anterior, no rompe con la estructura arquitectónica de la propia iglesia.

A partir de la segunda mitad del siglo XV, con estos maestros europeos se va a dar un gran desarrollo a las cabeceras de las iglesias, así como a las capillas funerarias de las naves. Éstas multiplican sus espacios tomando varios de los intercolumnios para la realización de un solo espacio, agrandándolas y rompiendo con el esquema uniforme de la construcción; o en las girolas, aumentando también el espacio en planta y altura y rompiendo, igualmente, con su anterior esquema unitario de los pequeños absidiolos. El resultado final del aumento de estos espacios funerarios en las cabeceras de las iglesias es la creación de grandes capillas funerarias en el presbiterio de iglesias de nave única, como es la Cartuja de Miraflores o San Salvador de Oña; o bien, la creación de grandes espacios centrales funerarios en la girola, en los absidiolos situados en línea con el altar mayor, como es el caso de la Capilla de los Condestables, estableciendo un fuerte eje axial en la Catedral con respecto al altar mayor y a esta capilla y donde, además, se crea un espacio propio, diferenciado del templo en el que se levanta, sin estar integrado en el mismo sino como una construcción aneja e independiente y que forma su propio templo, incluyendo su propia sacristía ${ }^{4}$.

Existían anteriormente espacios unitarios, como salas capitulares y otros espacios cuadrados u octogonales, que se cubrían con bóvedas únicas (tanto con alfarjes o artesonados, como con bóvedas de arista, de terceletes y, más tarde, estrelladas) que pueden reflejar, incluso, la influencia árabe en la Península.

No se puede olvidar la tradición islámica de la planta central, incluso para espacios funerarios en las qubbas o en sus semejantes cristianos, capillas cubiertas por cúpulas o bóvedas árabes, siendo más extraños en la Península pero numerosos en el Norte de África. Aquí se vinculan a construcciones árabes, en reutilizaciones de antiguas mezquitas islámicas convertidas en iglesias cristianas o en construcciones nuevas pero siempre con una fuerte impronta mudéjar, siendo la mayoría de ellas del siglo XIV aunque hay algunas anteriores. El mejor ejemplo es la Capilla Real de Córdoba,

\footnotetext{
4 Ibáñez nos da otros ejemplos como: "las capillas de la cabecera de la parroquial de San Gil como espacios propios de la iglesia, a diferencia de la capilla de la Natividad o de los Castro, que se ven y se sienten como espacios anejos". IBÁÑEZ PÉREZ, Alberto C., "Burgos en el siglo XV", en Actas del Congreso Internacional sobre Gil de Siloé y la escultura de su época (Burgos, 2001), Burgos, Institución Fernán González, 2001, p. 47.
} 
construida en la antigua mezquita como capilla funeraria de Alfonso XI, a modo de $q u b b a$. El más cercano lo encontramos en el monasterio de las Huelgas Reales de Burgos. En él vemos la Capilla de la Asunción ${ }^{5}$, con una más que probable utilización funeraria, con una planta cuadrangular cubierta con bóveda ochavada de dieciséis nervios sobre cuatro trompas angulares. Por todo ello, no hay que desligar la posible tradición árabe de las plantas centrales de todo tipo: salas capitulares, salones principales de los castillos (como los salones del trono que se realizan en los alcázares con una indiscutible pervivencia árabe o mudéjar) e, incluso, capillas funerarias.

Sin embargo, hay que pensar que la posible implantación en la Castilla gótica de la capilla central como capilla funeraria no desemboca de las plantas centrales árabes, sino de una tradición mucho anterior, de los martyria romano o los mausoleos imperiales reinterpretados en el mundo bizantino y carolingio ${ }^{6}$, siendo una arquitectura que no se abandona jamás, acogida por las diferentes reinterpretaciones del Santo Sepulcro u otras construcciones centrales, como las salas capitulares o los baptisterios exentos. Esta tipología central se aplica a las nuevas catedrales góticas. Además hay que pensar que el principal arquitecto de las primeras capillas funerarias centrales en Burgos, Juan de Colonia, conocería poco o nada de la arquitectura del sur de la Península, con lo que no puede haber tenido ningún modelo islámico en el qué inspirarse para sus creaciones. Y también hay que pensar que un mecenas como Alonso de Cartagena, encandilado con la arquitectura centro-europea (lo que se ve reflejado en la absoluta disposición de transformar su catedral francesa en un fiel reflejo de las alemanas), no pensaría en las qubbas islámicas como modelos de su propia capilla funeraria.

Según mi parecer, se puede pensar en una influencia islámica en la introducción de los calados en las bóvedas de crucería de las capillas y cimborrios como, por ejemplo, en la bóveda de la Capilla del Condestable. Aunque también hay que pensar que el calado de las bóvedas es el reflejo de la disolución de estructuras que ya se estaba dando, mediante la tracería, en las flechas alemanas o los tabernáculos flamencos y las estructuras traslucidas de ventanales, óculos y triforios. Por tanto, pienso que esta solución de calar las bóvedas que, además, se comienza a dar más tardíamente, a finales del siglo XV cuando ya ha podido calar la tradición árabe en la segunda generación de arquitectos extranjeros, es en este caso una convergencia evolutiva ${ }^{7}$

\footnotetext{
5 "No dudamos que siempre fue capilla, que reaprovecha un ámbito sagrado anterior, y de que fue concebido, posiblemente, como oratorio de carácter funerario. Si en su centro estuvieron los sarcófagos exentos de los reyes fundadores, tal como dice la tradición, nos hallaríamos ante un espacio netamente islámico". RUIZ SOUZA, Juan Carlos, "La planta centralizada en la Castilla bajomedieval, entre la tradición martirial y la qubba islámica. Un nuevo capítulo de particularismo hispano", en Anuario del Departamento de Historia y Teoría del Arte, vol. XIII, 2001, pp. 16-18. Por su parte, Pilar Alonso Abad nos dice que esta capilla "es reconocida como la antigua iglesia del palacio, de estilo almohade. Tuvo la función de capilla funeraria hasta que en 1279 se trasladaran los sepulcros de los Fundadores aquí situados, a su lugar definitivo en la iglesia". ALONSO ABAD, María Pilar, La actividad artística en el Monasterio de Santa María la Real de las Huelgas de Burgos, Burgos, Tesis Doctoral de la Universidad, 2003, p. 799.

6 O en el mundo prerrománico alemán, como ya vimos en la Iglesia de San Gereón de Colonia. CARAZO, Eduardo y OTXOTORENA, Juan Miguel (1994), op. cit., p. 65.

7 Ruiz Souza es uno de los que más habla de convergencias evolutivas en la arquitectura tardogótica entre el arte islámico y el de tradición cristiana. RUIZ SOUZA, Juan Carlos (2001), op. cit., pp. 23 y 24.
} 
de influencia islámica que, obviamente, tiene una gran tradición de la decoración calada y translúcida y de influencia centroeuropea, con esta tendencia a la disolución de estructuras.

En los últimos estudios sobre Juan de Colonia y sus trabajos en Burgos, se comienza a asegurar que fue éste quien introduce en Castilla la bóveda "de terceletes y cinco claves, enriquecida con nervios rectos en torno a la clave polo y, además, habría que añadir, ornada con caireles" ${ }^{8}$. Es posible que la bóveda de terceletes compleja sea una introducción realizada por Juan de Colonia. Pero hemos de tener en cuenta que las bóvedas de terceletes sencillas son anteriores ${ }^{9}$ y que la introducción de los caireles no se da hasta la intervención de Simón de Colonia en los trabajos de su padre, como en las bóvedas de la Cartuja. Igualmente, no debemos pensar tampoco en la posibilidad de la introducción de las bóvedas estrelladas en Castilla por Juan de Colonia, ya que anteriormente también encontramos bóvedas de ocho puntas, como la de la Capilla de Santa Catalina de la Catedral burgalesa o la capilla de Arnaldo Barbazán en el claustro de la Catedral de Pamplona ${ }^{10}$. Lo que sí es cierto es la fácil superación por los arquitectos alemanes de las dificultades técnicas propias de este tipo de bóvedas, derivadas de las transformaciones de los alzados cuadrangulares en cubiertas octogonales, mediante tambores, semibóvedas ${ }^{11}$, trompas y pechinas, utilizados siempre en la construcción de las torres y flechas, pudiendo conseguir que las bóvedas se complicasen llegándose, incluso, a calar. Juan de Colonia utiliza estas semibóvedas en sus obras de igual manera que son utilizadas en el siglo XIV. A partir de la construcción de la capilla de los Condestables se comienzan a realizar trompas propiamente dichas, imponiéndose en la escuela burgalesa a diferencia de la toledana, que seguirá con estos terceletes. Estas trompas son una estructura que el románico ya conocía pero que había desaparecido durante el gótico. De esta forma, hay un corte claro entre la arquitectura de Juan y Simón de Colonia. Sin embargo, no podemos decir que Juan no conociera las trompas que sí utiliza en las agujas de la catedral burgalesa (para pasar de la planta cuadrada de la torre a la octogonal de la aguja), sino que no las emplea en las construcciones más nobles, como pueden ser las capillas funerarias. Es Simón quien las emplea en sus grandes construcciones, comenzando a decorarlas como veneras ${ }^{12}$.

Igualmente, debemos otorgar a Simón de Colonia la construcción de bóvedas con combados en la escuela burgalesa y la introducción de caireles que decoran las bóvedas que, en muchos casos, está ligada a la arquitectura funeraria. Estas decoraciones

8 GARCÍA CUETOS, María Pilar (2010), op. cit., pp. 123-124. Y "gracias a Juan de Colonia, la estrella de terceletes y cinco claves, novedosa en sí misma, se enriqueció con nervios rectos adicionales en torno al polo (capilla de la Visitación o de Alonso de Cartagena en la catedral de Burgos, 1440-1442)". GÓMEZ MARTÍNEZ, Javier, "El arte de la montea entre Juan y Simón de Colonia", en Actas del Congreso Internacional sobre Gil de Siloé y la escultura de su época (Burgos, 2001), Burgos, Institución Fernán González, 2001, pp. $364-366$.

9 Tenemos un buen ejemplo en la capilla de los Rojas de la Catedral de Burgos del siglo XIV.

10 ALONSO RUIZ, Begoña, Arquitectura tardogótica en Castilla: Los Rasines, Santander, Servicio de Publicaciones de la Universidad de Cantabria, 2003, p. 149.

11 Estas semibóvedas son las que, a modo de trompas nervadas o de terceletes de tres nervios y una clave, con planta triangular, hacen que el cuadrado pase al octógono.

12 GÓMEZ MARTÍNEZ, Javier (2001), op. cit., pp. 358-360. 
de caireles vienen de la arquitectura alemana de los Parler que después asimilará la escuela de Ulrico von Esingen, con algunos ejemplos de las escuelas alemanas en Frankfurt, Praga o Meisenhein. Estas dos características de Simón son las que han llevado a algunos historiadores a plantearse una posible visita al lugar de origen de su padre, donde adquiriría algunas técnicas que Juan desconocía y que se desarrollaron después de su viaje a Castilla ${ }^{13}$.

El primer modelo en la Catedral burgalesa de una capilla centralizada y cubierta con bóveda de crucería es la capilla de Santa Catalina. Fue construida por el obispo Gonzalo de Hinojosa a partir de 1316. Sobre una planta cuadrada se proyectó una bóveda de crucería octopartita, pasando del cuadrado al octógono por estos terceletes triangulares de los que ya hemos hablado, a la manera que se seguirá realizando en el siglo XV. Los nervios de la bóveda desembocan en unas finas columnillas coronadas por capiteles corridos y que terminan en ménsulas que, junto a los capiteles y claves, están decoradas y policromadas con escenas cortesanas y de caza. Pero como decía, nunca se ha dado la importancia requerida a esta capilla, pasando más o menos desapercibida en los estudios de la Catedral y de la arquitectura burgalesa, a pesar de ser una de las precursoras directas de las capillas funerarias que, más tarde, construirán los Colonia y su entorno y de ser esta bóveda octopartita un claro precedente de bóvedas como la de San Salvador de Oña o la de la capilla de la Presentación.

Asimismo, a finales del siglo XIV encontramos una capilla funeraria cubierta con bóveda de terceletes, situada en el transepto, siendo también un antecedente de las capillas funerarias que vamos a ver en la segunda mitad del siglo XV. Es la antigua capilla de los Rojas o de Santa Catalina, que hoy forma la denominada de San Juan de Sahagún. Fue elegida por María de Rojas como lugar de sepultura para su familia. En las claves de las bóvedas se pueden ver los escudos de los fundadores, las estrellas de los Rojas.

Como decíamos antes, a partir de la construcción de la capilla de la Visitación de la Virgen, encargada seguramente a Juan de Colonia en 1440 por el Obispo Alonso de Cartagena como capilla funeraria, se inicia un periodo de construcción de capillas funerarias que transforman el aspecto de la plantas de las catedrales ${ }^{14}$. Juan de Colonia es quien introduce en el gótico burgalés y, por tanto, en el castellano la concepción del espacio arquitectónico único, diáfano y amplio como espacio funerario (fig. 1). Ya vemos como las capillas funerarias centrales no generan una innovación técnica dentro de la arquitectura gótica, pero sí que son una innovación su utilización, su situación, su monumentalidad (mayor con el tiempo) y, sobre todo, su difusión en este momento.

Esta importante capilla fue realizada entre el 17 de febrero de 1440, cuando el obispo consigue el permiso del cabildo para la construcción, al 6 de abril de 1442,

13 La teoría de que fue Simón de Colonia el autor de los primeros combados en España avalaría su presencia temporal en Alemania, pues es allí donde se realizaron los primeros combados. GÓMEZ MARTÍNEZ, Javier, El Gótico español de la Edad Moderna. Bóvedas de Crucería, Valladolid, Universidad de Valladolid, 1998, pp. 90-94; y GARCÍA CUETOS (2010), op. cit., pp. 129-130.

14 En realidad, no hay ningún documento que acredite la mano de Juan de Colonia aquí, pero la tradición y los estudios formales y estilísticos siempre le han dado su autoría sin ningún tipo de duda. 


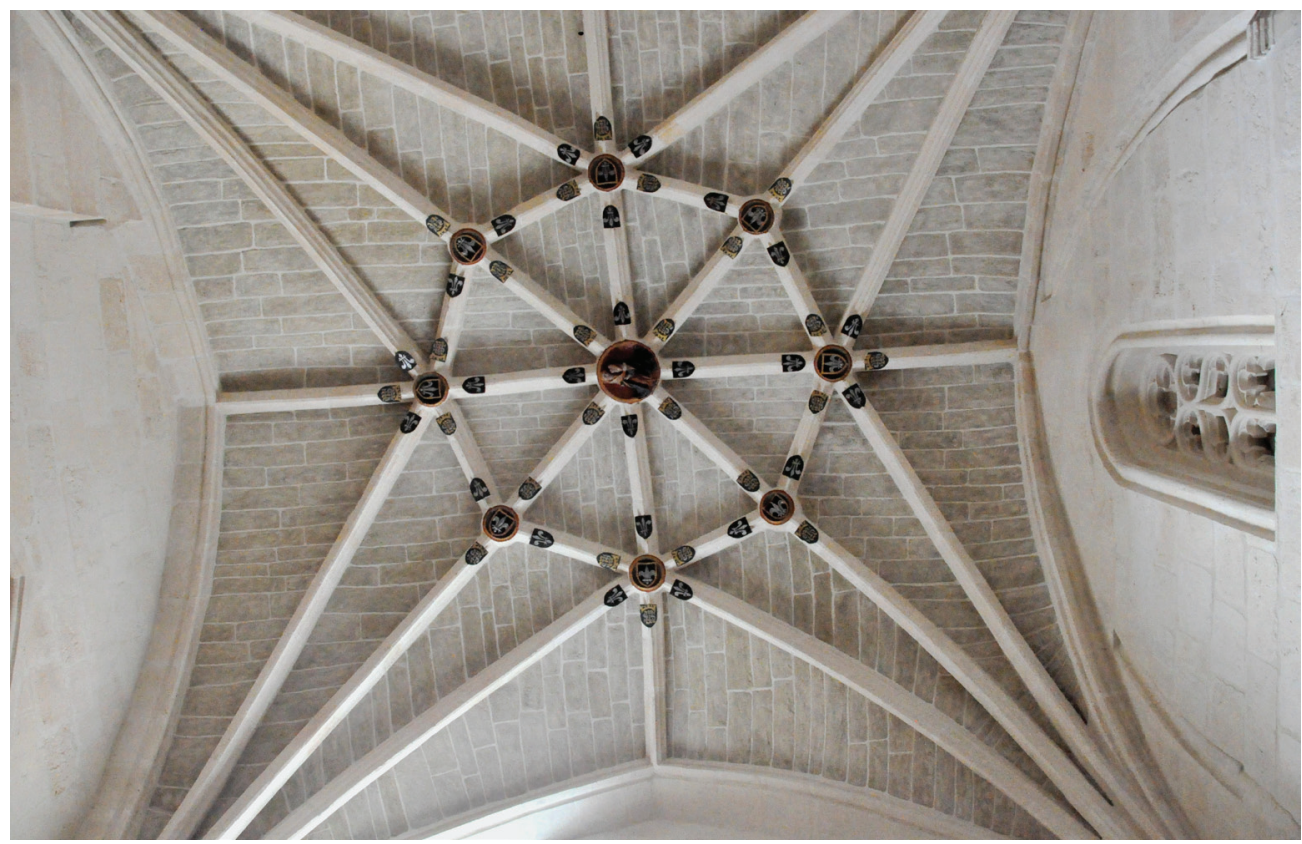

Fig. 1. Juan de Colonia, Capilla de la Visitación, Catedral de Burgos, ca. 1440-1442, bóveda.

fecha en la que ya se habla de que la capilla estaba completa. Se utilizaron para su construcción capillas anteriores, divididas por un contrafuerte que hace que el espacio quede dividido en dos, construyéndose dos bóvedas diferenciadas. El espacio principal se halla cubierto por una bóveda de terceletes, cuyas claves secundarias se encuentran unidas entre sí mediante nervios secundarios, formando un octógono. El espacio de la cabecera, menor, se cubre con una bóveda de terceletes más simple, simétrica solo a dos ejes, únicamente con dos de los cuatro terceletes. Aunque vemos como el espacio se encuentra realmente dividido en dos, en su interior se da una gran sensación de amplitud, potenciada sobre todo por la bóveda principal, muy novedosa para el momento y por la situación central del sepulcro del obispo que une estos espacios. La base del sepulcro de Alonso de Cartagena probablemente está realizada por algún colaborador de Juan de Colonia, quizá Pedro Fernández de Ampuero y la efigie del prelado realizada seguramente por Gil de Siloé con posterioridad, según las últimas teorías ${ }^{15}$. En la capilla aparecen otros sepulcros de familiares y allegados de

15 ANDRÉS ORDAX, Salvador, "El otoño de la Edad Media. La Catedral de Burgos en el siglo XV", en PAYO HERNANZ, René J., La Catedral de Burgos. Ocho siglos de Historia y Arte, Burgos, Diario de Burgos, 2008, p. 226. Gómez Bárcena nos da las diferentes teorías de la posible construcción de este sepulcro, de indudable influencia flamenca, pero demasiado temprano en su ejecución si fuera contemporáneo a la capilla. GÓMEZ BÁRCENA, María Jesús, Escultura gótica funeraria en Burgos, Burgos, Exma. Diputación de Burgos, 1988, pp. 52-53. 
Alonso de Cartagena. El propio Juan de Colonia tiene su enterramiento aquí. En 1521 fue añadida la sacristía realizada por Nicolás de Vergara el Viejo y Juan de Matienzo.

Otra de las capillas funerarias más importantes en Burgos, también comenzada por Juan de Colonia, es la Capilla de la Concepción o de Santa Ana. Fue realizada entre los años 1477, con permiso otorgado por el Cabildo el 25 de enero, y 1488 como capilla funeraria del obispo Luis de Acuña y Osorio, sucesor de Alonso de Cartagena ${ }^{16}$. A su muerte, en 1481, su hijo Simón heredó el cargo de maestro mayor de la Catedral, continuando con las obras de su padre en las que, seguramente, ya había estado trabajando. Una de las características más destacadas de esta capilla es su disposición, simétrica en planta con respecto a la de su predecesor, es decir, que está situada en el crucero Norte. Sus bóvedas, seguramente proyectadas por Juan de Colonia, fueron finalizadas por Simón, lo que se evidencia en la aparición de caireles decorando los nervios. La compleja bóveda es un alarde de experimentación en una planta irregular, ya que parecen dos bóvedas simples de crucería pero sin un fajón medianero que las separe, actuando como tal uno de los terceletes (fig. 2). Los nervios de ambas bóvedas se unen por las claves formando dos estrellas, una regular y simétrica de terceletes con cuatro puntas, la principal, y otra irregular de seis puntas. Una vez más, este hecho hace que el espacio se unifique otorgando gran centralidad a la capilla. En el centro de la misma se encuentra el sepulcro del obispo, realizado posteriormente a su muerte por Diego de Siloé.

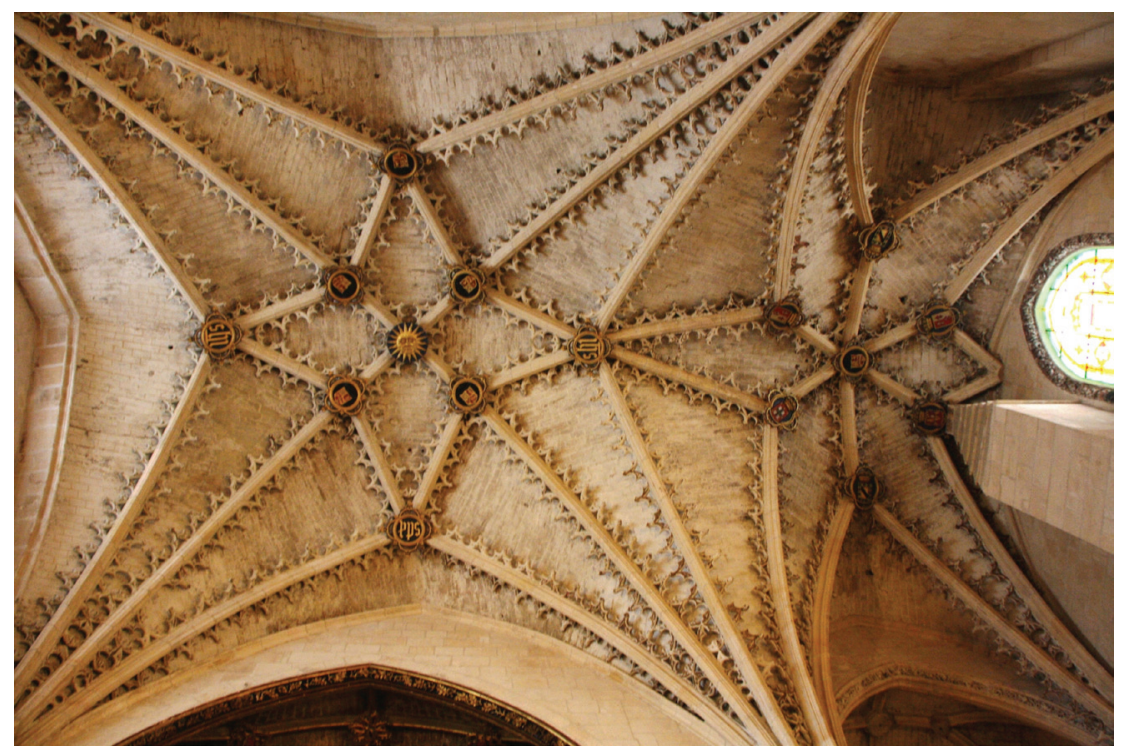

Fig. 2. Juan y Simón de Colonia, Capilla de la Concepción o de Santa Ana, Catedral de Burgos, 1477-1488, bóvedas.

16 Tampoco hay ningún documento que demuestre la mano de Juan de Colonia, pero este ya era maestro de la Catedral y estaba finalizando la flecha Norte, por lo que es totalmente lógico que realizara la capilla funeraria del obispo del momento. 
Por último, dentro de la Catedral y del siglo XV, está la Capilla de la Purificación, más conocida como Capilla de los Condestables. Fue encargada por Pedro Fernández de Velasco y Mencía de Mendoza al maestro de la Catedral, Simón de Colonia, en 1482. Es la obra funeraria más importante de la catedral, concebida como un espacio independiente dentro del templo, incluso con su propia sacristía. Su situación dentro de la Catedral es también significativa, estando situada en el centro de la girola, detrás del altar mayor, como ya indicamos. Las obras arquitectónicas fueron finalizadas en 1494, teniendo aún que realizarse algunas obras menores (como los pináculos del exterior) y el amueblamiento y decoración escultórica del interior. Debía estar casi completamente acabada a la muerte de Doña Mencía, en $1500^{17}$. En 1517 Francisco de Colonia realiza la sacristía adosada (fig. 3).

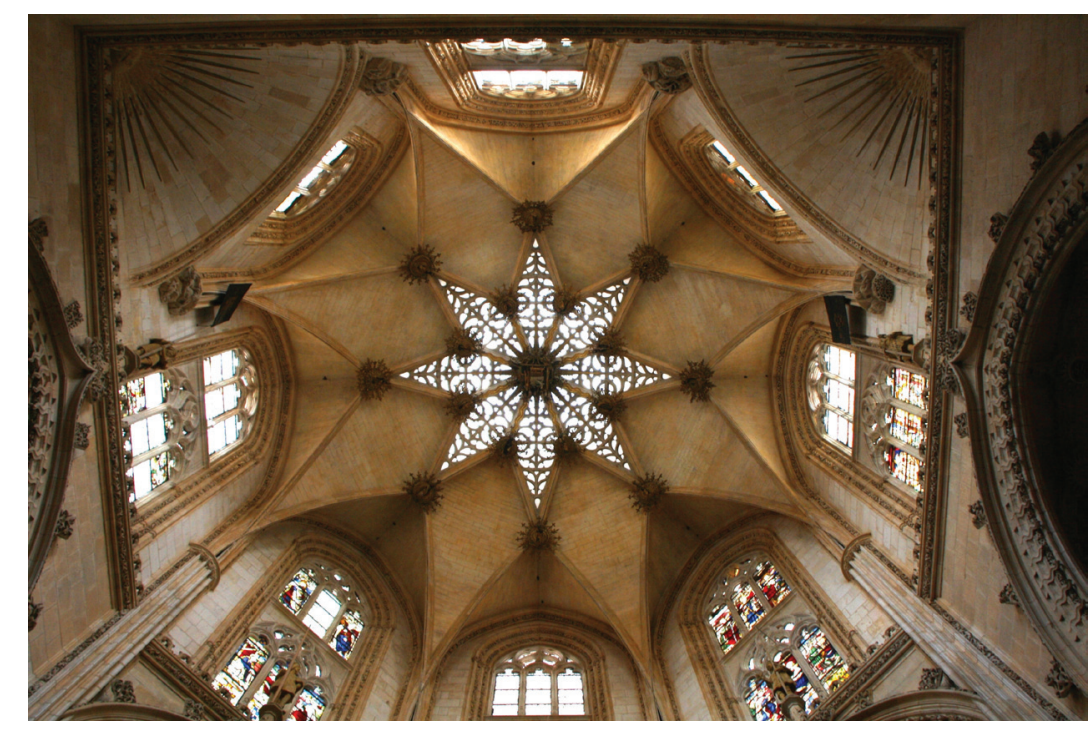

Fig. 3. Simón de Colonia, Capilla de los Condestables, Catedral de Burgos, 1482-1494, bóveda.

La capilla se estructura mediante una planta octopartita, un tanto irregular debido al terreno donde se asienta y a construcciones anejas. Su alzado se estructura en tres partes bien diferenciadas, un gran muro inferior sin ningún tipo de abertura al exterior, donde se asienta mucha de la escultura monumental de la capilla; una parte intermedia, donde se sitúa el gran triforio profusamente decorado; y la parte superior, con un doble juego de ventanas enmarcadas por los baquetones decorados con vegetal. Toda la estructura ochavada se cubre por una compleja bóveda de crucería estrellada octopartita con la plementería calada. En los lados donde la capilla se une a la girola de la Catedral, se hallan las dos grandes trompas que actúan tanto como unión física

17 ANDRÉS ORDAX, Salvador (2008) op. cit., p. 242. 
con la girola, como de sustento a la propia estructura de la bóveda estrellada. Por debajo de éstas se halla la pequeña bóveda que, actuando como una especie de nártex, se sitúa a la entrada de la capilla. Hay que destacar que esta bóveda está realizada con combados, a la manera que Simón de Colonia estaba ya realizando.

Es destacable la profusa decoración escultórica de la capilla, sobresaliendo tanto la escultura monumental como los sepulcros de sus fundadores. Estos se hallan en el centro de la capilla, ornados con ricas vestimentas y con una gran calidad. Se trata de una obra atribuida a Felipe Vigarny, realizada entre 1525 y 1532. Por su parte, la capilla tiene tres grandes retablos, el de Santa Ana realizado por Gil de Siloé; el retablo de San Pedro y el retablo mayor, por Diego de Siloé y Felipe Vigarny.

Los antecedentes de esta capilla son las que hemos estado viendo hasta ahora y sus influencias van a ser infinitas, tanto en la ciudad burgalesa como en la provincia y en toda Castilla. Es, asimismo, la primera bóveda calada de la arquitectura burgalesa, dando a la luz una importancia que no había tenido hasta el momento en las construcciones. La plementería calada y el entrecruzamiento de los nervios son dos de las características más importantes de esta capilla, al igual que la aparición por primera vez de trompas, como ya indicamos antes, decoradas en este caso con rayos solares. Por su parte, su planta ochavada será la que más va a influir en la arquitectura funeraria posterior, siendo la referencia inmediata tanto de capillas funerarias como de templos posteriores. E, incluso, la estructuración de las partes del alzado de la capilla será realizada por el propio Simón de Colonia varias veces e imitada, posteriormente, en otras capillas funerarias. La repercusión de esta capilla funeraria, mandada construir por los nobles más importantes del reino castellano a uno de los arquitectos más reputados, fue tal que significó la imitación de estos actos por todo aquel que quisiera ser o aparentar ser alguien en la sociedad del momento. Algunas de las obras más influidas por esta capilla, construidas ya en el siglo XVI, son las anejas en la catedral, como la de La Natividad, construida por Ana de Espinosa como capilla funeraria de Pedro González de Salamanca y, sobre todo, la Capilla de la Presentación, construida por Juan de Matienzo en 1521, evocando claramente la capilla de los Condestables en sus bóvedas, como capilla funeraria de Gonzalo Díaz de Lerma.

Fuera de la Catedral de Burgos tenemos muchos ejemplos de capillas funerarias en las diferentes iglesias y monasterios de Burgos. Algunas de ellas se encontraban en iglesias hoy desaparecidas, como es el caso del Monasterio de San Juan, reconstruido por Juan de Colonia y reformado constantemente en el siglo XVI. El ejemplo más notable de estas reformas es la Capilla de Monserrat, antigua Sala Capitular y lugar de enterramiento de los monjes, que se caracteriza por ser una gran sala cuadrada con cuatro grandes columnas que dividen el espacio en nueve tramos cubiertos con bóvedas de terceletes.

Lo mismo ocurre con el desparecido convento de San Pablo cuyas capillas funerarias, además de la propia capilla mayor, panteón funerario del obispo Pablo de Santamaría, habían sido construidas por doquier durante el siglo XV y XVI. Muchas de ellas eran de ámbito único, como la capilla de las Once Mil Vírgenes, construida a finales del siglo XV y presumiblemente cubierta con una bóveda estrellada y con el sepulcro de los Maluenda situado en su centro. O la Capilla del Rosario, renombrada 
en el siglo XVII como de Santo Domingo, construida por Francisco de Colonia a principios del siglo XVI en uno de los laterales del transepto como una gran capilla cuadrangular, cubierta con una bóveda del gótico avanzado ${ }^{18}$. También en el monasterio de San Pablo encontramos ejemplos más tardíos del siglo XVI, que nos dejan ver la influencia de los espacios centrales en la arquitectura funeraria de la siguiente centuria. Es el caso de la capilla de San Gregorio, realizada por Juan de Vallejo, un espacio cuadrado en planta pero ochavado en altura, lo que nos está indicando una bóveda estrellada octopartita sobre pechinas y posiblemente calada, para la familia de los Gallo.

Tenemos muchos otros ejemplos, como la iglesia construida como mausoleo familiar de Juan de Ortega, Santa Dorotea o, la más conocida, la iglesia de San Nicolás por la familia Polanco. Esta iglesia, construida entre finales del siglo XV y principio del XVI, si bien con tres naves al modo tradicional, en realidad tiene una planta casi cuadrada. Su interior se articula con cuatro grandes haces de columnillas que sustentan las nueve bóvedas de crucería que conforman la cubierta. Aunque la iglesia está llena de arcosolios y sepulcros, destacan los cuatro del altar mayor. En la parte baja, a los lados del gran retablo de piedra construido por Simón de Colonia y su hijo Francisco, están los sepulcros de Alfonso de Polanco y Constanza Maluenda y de Gonzalo López de Polanco y Leonor de Miranda. Es una iglesia configurada y realizada para ser panteón funerario, lo que es algo insólito y desmesurado para un mercader ${ }^{19} \mathrm{y}$ se podría pensar, por tanto, que su configuración cuadrangular tiene relación con su función funeraria.

En la iglesia de San Gil se construyen varias capillas funerarias en el siglo XV realizadas por nobles, como la reforma de la capilla mayor realizada por Diego de Soria y Catalina de Maluenda en 1486. A su izquierda se halla la capilla de la Buena Mañana, ocupando los dos tramos de la cabecera y cubierta por una gran bóveda de terceletes con las claves decoradas. Fue realizada por Garci Martínez de Mazuelo y Alonso de Lerma. A su derecha, la Capilla de los Reyes Magos, construida en 1489 por Fernando de Castro y Juana García de Castro. También la Capilla de los Burgos, construida por los García de Burgos y una de las ramas de los Polanco, es del siglo $\mathrm{XV}$. El resto de capillas fueron construidas en la siguiente centuria, siendo algunas de ellas un fiel reflejo de la influencia de la Capilla de los Condestables de la Catedral, como la Capilla de la Natividad de María construida seguramente por Juan de Matienzo en 1529 para Juan de Castro e Inés de Lerma. En ella destaca su enorme bóveda estrellada octogonal, con la plementería calada en un rosetón central, apoyada sobre pechinas aveneradas.

En la iglesia de San Lesmes, relacionada con el círculo de Simón de Colonia y remodelada a finales del XV, encontramos muchos sepulcros a lo largo de sus paredes.

18 CASIllas GARCÍA, José Antonio, El convento de San Pablo. Historia y Arte, Burgos, Excma. Diputación Provincial de Burgos, 2003, pp. 226-227.

19 "La iglesia de San Nicolás, ni parroquial ni monacal ni de cofradía gremial, fue levantada por el mercader López de Polanco con la única finalidad de servir para enterramiento familiar. Obra que, de acuerdo con la opinión del profesor Yarza Luaces, nos parece un 'exceso difícilmente explicable"'. IBÁÑEZ PÉREZ, Alberto C. (2001), op. cit., p. 46. 
Entre los sepulcros de arcosolio de la capilla mayor están los de Fernando Medina y Beatriz del Castillo, el de Diego del Campo o el de la familia Valladolid, todos ellos de principios del XVI, convirtiendo el ábside central en una gran capilla funeraria. Pero en esta iglesia destaca sobre todo el sepulcro de San Lesmes situado en medio de la nave central, realizado a finales del siglo XV por el Maestro de Covarrubias. Igualmente, destaca la capilla de los Salamanca, realizada en el lado de la epístola, de planta cuadrangular y cubierta con bóvedas de crucería, de finales del siglo XV. Su fundador fue García de Salamanca, gran protector de la capilla. Su sepulcro y el de su esposa estaban dispuestos originalmente delante del altar (hoy se encuentran en el muro) y datan de principios del siglo XVI.

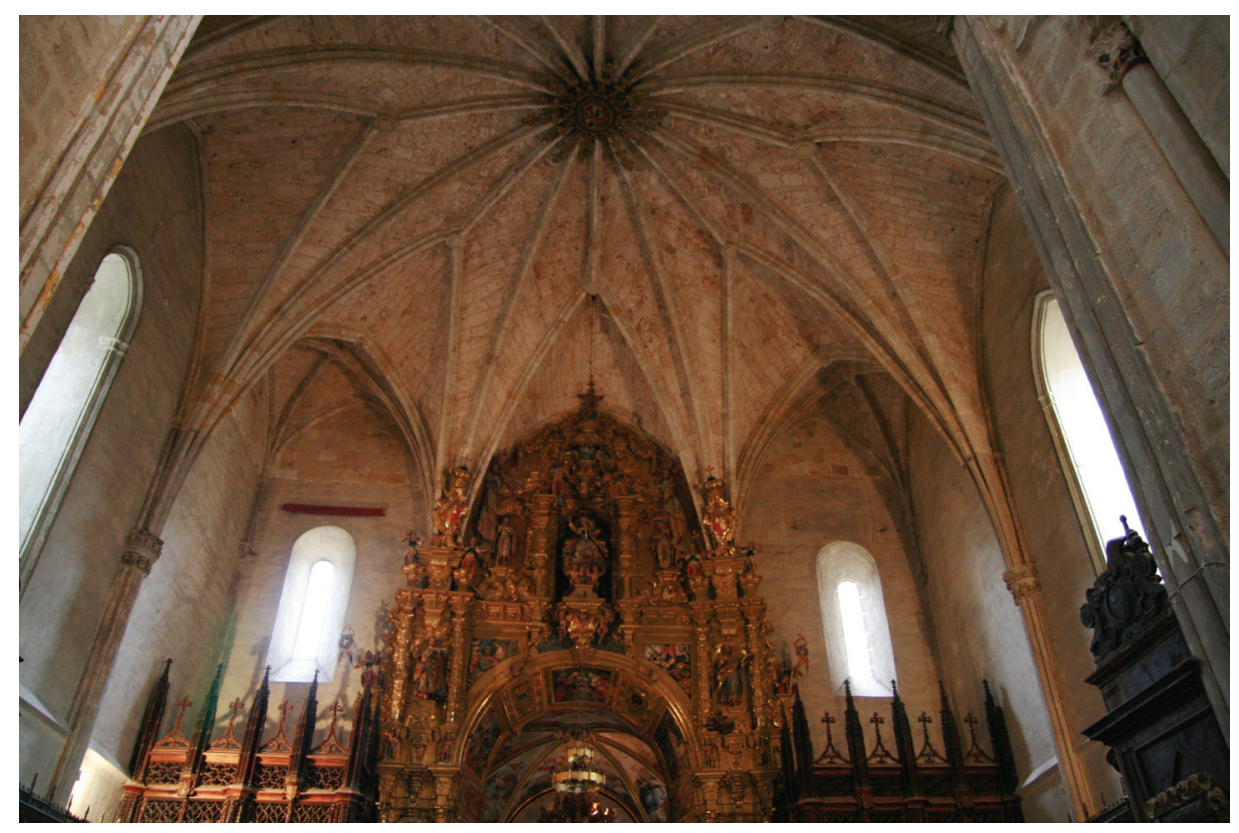

Fig. 4. Fernando Díaz de Presencio, Monasterio de San Salvador de Oña (Burgos), ca. 1460-1470, ábside de la iglesia.

También son importantes aquellas iglesias monasteriales que han reestructurado su planimetría para adaptarla a las necesidades de ser un panteón, en los casos que nos ocupan, reales. Es el caso de la iglesia de San Salvador de Oña, con una gran cabecera única cubierta con una gran bóveda estrellada, construida por Fernando Díaz de Presencio entre 1460 y 1470, apenas 20 años después de la llegada de Juan de Colonia a Burgos. Siempre se ha creído que Fernando Díaz, constructor también de la Colegiata de Covarrubias, fue discípulo del maestro alemán, pudiendo aprender la configuración de los espacios centrales de su mano. Desde un grandísimo espacio cuadrangular nace una bóveda octogonal, con pequeñas pechinas nervadas en las esquinas, configurando una gran bóveda estrellada (fig. 4). De esta manera, se crea un 
espacio unitario y cerrado con proporciones armónicas y regulares y con un sentido proyectante, axial hacia el ábside y hacia el lugar donde se encuentra el gran panteón de los Reyes y Condes de Castilla. Además, en este espacio se juega con diversos factores, como con la luz, ya que está mucho más iluminado que el resto; con las formas, por la gran bóveda que destaca sobre las bóvedas de terceletes de la nave y porque el altar y los panteones están elevados con respecto a la nave; y con la decoración, ya que resalta por los panteones de madera con pinturas y por la gran clave central con las armas de Sancho II. La repercusión de esta tipología es mucha: las iglesias de Santo Tomás de Arnedo, San Juan Bautista de Santoyo y Santo Tomás de Haro son imitaciones más sencillas de la iglesia de Oña. Pero, además, Oña es una de las construcciones pioneras de un modelo difundido en España por los Reyes Católicos, con ejemplos tan importantes como San Juan de los Reyes en Toledo, Santo Tomas de Ávila o el Monasterio del Parral de Segovia.

Otra de las construcciones que también configuran la tipología que se va a desarrollar con los Reyes Católicos es la Cartuja de Miraflores de Burgos ${ }^{20}$. Estamos ante una iglesia con una gran nave única que finaliza en una capilla mayor que aumenta sus dimensiones con respecto a las de la nave. Esta situación viene dada por la presencia en su interior de los grandes sepulcros reales de Juan II e Isabel de Portugal, que ocupan gran parte de la capilla. La Cartuja fue comenzada por Juan de Colonia hacia 1452 quien seguramente diseñó la traza de la iglesia. A su muerte, fue continuada por Garci Fernández de Matienzo y concluida por Simón de Colonia hacia 1499. La presencia de este arquitecto se ve en los caireles de los nervios de la bóveda de la capilla mayor, típica firma de las obras del segundo de los Colonia (fig. 5).

El espacio interior se divide en cuatro tramos. Los tres primeros están cubiertos por bóvedas de terceletes complejas, a la manera de las de Juan de Colonia, siendo diferente la más cercana a la cabecera que se complica más que las otras. La cabecera, más ancha que la nave, es poligonal y está cubierta con bóvedas de terceletes en el tramo recto, mientras que se cierra con una compleja bóveda de nervios semi estrellada, donde aparecen sus nervios principales decorados con caireles. La cabecera alberga las tres joyas de la Cartuja realizadas por Gil de Siloé: el retablo mayor, los sepulcros de Juan II e Isabel de Portugal y el sepulcro del Infante Alfonso. El sepulcro exento de los reyes es, además, un ejemplo singular, tanto en su forma como en su decoración. El talud tiene forma estrellada de ocho puntas y encima se sitúan las imágenes de los monarcas, representados como estatuas con peana y doseletes en la cabeza. Por su parte, el sepulcro del Infante Alfonso se encuentra en el muro septentrional en un arcosolio. La figura del Infante se encuentra orante en vez de yacente, mirando al altar, junto a un pequeño reclinatorio con un libro de horas. Estas obras hacen destacar la capilla mayor que, junto a su cubierta y su pequeño elevamiento y ensanchamiento con respecto a la nave, potencian la axialidad de la iglesia y dan importancia y relevancia al panteón funerario.

Este modelo de capillas ochavadas (tanto en las Capillas Mayores de las iglesias como en capillas adosadas) con uso funerario triunfará en el siglo XVI a medida que

20 GARCÍA CUETOS, María Pilar (2010), op. cit., pp. 123-127. 


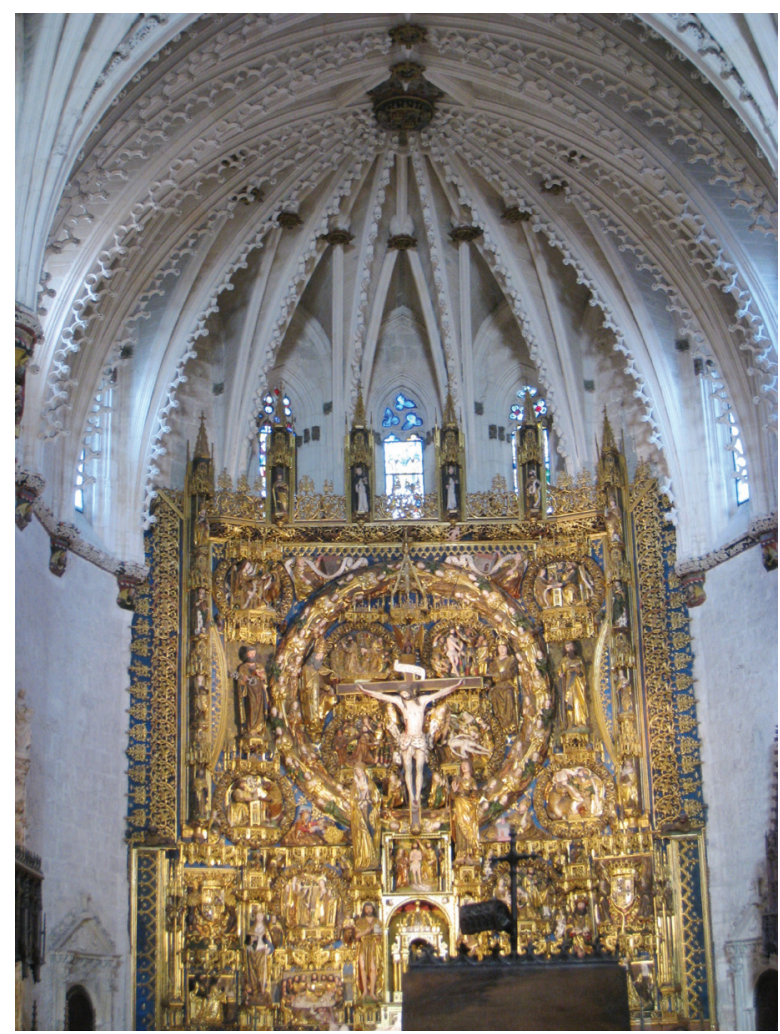

Fig. 5. Juan de Colonia, Garci Fernández de Matienzo y Simón de Colonia, Cartuja de Santa María de Miraflores (Burgos), ca. 1452-1499, ábside de la iglesia.

avanza la centuria. Aunque su origen es puramente burgalés gracias a las tres generaciones de arquitectos ligados a los Colonia, lo encontramos diseminado por todo el país. Y, sobre todo, gracias al mecenazgo de eclesiásticos y nobles que, a imitación de los grandes condestables y de los grandes obispos burgaleses, quieren construirse sus grandes panteones. Como Begoña Alonso y otros ${ }^{21}$ ya han estudiado, hubo una importante generación de maestros trasmeranos que adquirió sus conocimientos en Burgos con los Colonia y que llevó consigo todo lo aprendido, imponiendo su modo de construir en todo el norte peninsular.

Además, los sucesores de los primeros condestables son quienes realizan algunas de las fundaciones de capillas funerarias, influidas directamente por la Capilla de los Condestables y construidas por los maestros herederos de los Colonia. Se trata de capillas independientes, como la Capilla de la Concepción en el Monasterio de Santa

21 ALONSO RUIZ, Begoña (2003), op. cit., y PAYO HERNANZ, René J. e IBÁÑEZ PÉREZ, Alberto C., Del Gótico al Renacimiento: artistas burgaleses entre 1450 y 1600, Burgos, Cajacírculo, 2008, pp. 51 y 58-59. 
Clara de Medina de Pomar. O capillas mayores de iglesias monasteriales, como la cabecera de Santa Clara de Briviesca o la del Monasterio de La Vid.

Además de las que ya hemos ido nombrando anteriormente, hay otros ejemplos en toda la provincia, como la Colegiata de Peñaranda de Duero, posiblemente de Rodrigo Gil de Hontañón; o la Capilla de los Burgos en Roa de Duero. Y fuera de Burgos, la capilla del Santo Cristo en San Severino de Valmaseda o la Capilla de los Escalante en Laredo, ambas de Juan de Rasines.

En fin, son una serie de construcciones influidas directamente por la Capilla de los Condestables de la Catedral de Burgos, basadas en ser espacios diáfanos y cuadrangulares cubiertos por bóvedas estrelladas de ocho puntas, muchas veces caladas, sobre trompas normalmente aveneradas, consiguiendo un gran espacio único y cerrado, con gran importancia de la luz y de la centralidad. Es, además, una tipología típica en las construcciones de la Escuela Burgalesa y de sus arquitectos. Igualmente se caracterizan por su cercanía en el espacio temporal, vinculadas al Norte de la Península en el siglo XVI. Pero como hemos estado viendo, estas capillas son la conclusión de una tipología que comienza antes del siglo XV, se desarrolla durante este siglo y tiene su máximo ejemplo en la Capilla de los Condestables, que influirá en todas las construcciones funerarias del siglo XVI. 